\title{
Post Endodontic Restoration: Are You Serious?
}

\author{
Dr. Vandana B. Kokane ${ }^{1}$, Dr.Swapnil N.Patil ${ }^{2}$ \\ ${ }^{1,2}$ (Departmentof Conservative dentistry, VSPM dental college , Nagpur, MUHS Nashik University, India)
}

\begin{abstract}
After root canal obturation of sound posterior teeth, dentists are always in hurry of giving full crown. They are not serious in giving proper post endodontic restoration which results in fracture of tooth or restoration, if patient delays the full crown treatment. The inherent causes of failures are rarely evaluated. Thus, it was the purpose of this study to analyze the opinion of practicing dentist and after 24 months of clinical observation to present a logical approach to this subject as the final success of endodontic treatment is depend on the proper and timely coronal restoration.
\end{abstract}

Keywords: fracture, full crown, Obturation, post endodontic restoration, posterior teeth,

\section{Introduction}

Endodontic therapy is no longer practiced only by endodontist, but is generally practiced by the entire profession. These large numbers of teeth being treated endodontically makes it imperative for the dentist to be capable of providing satisfactory restoration for these teeth to remain intact within the dental arch as an integral functioning component. It has been stated that root canal therapy saves the root whereas restoration reinstates the tooth as a functional member of the masticatory system. To accomplish this objective, the restorative procedure should be primarily concerned with prevention of tooth fracture. ${ }^{[1]}$

Much stress has been given to elaborate post endodontic restoration, which requires post and core. Less literature support is present on post endodontic restoration of tooth, which do not require post and core. The forces on posterior teeth are predominantly vertical, therefore reinforcement of coronal tooth structure is not commonly needed if there is adequate tooth structure and proper restoration is done after endodontic treatment. ${ }^{[2]}$ Hunter A.J. in 1989 stated that $80 \%$ of endodontically treated teeth with conservatively enlarged root canals can be restored without a post, provided sound treatment goals are followed. ${ }^{[3]}$

Anil Kishan (2006) in his well elaborated article explained even though loss of tooth structure is an important factor that diminishes fracture resistance in endodontically treated tooth, this reason does not fully explained, why endodontically treated teeth with minimal loss of tooth structure became susceptible to fracture particularly overtime ${ }^{[4]}$.

During my 25 years of clinical practice, I noticed that not only general dental practitioner, even specialty practitioner are also not serious in giving proper post endodontic restoration. This results in crown fracture of satisfactorily root canal treated tooth, having sufficient amount of tooth structure, within six months of post endodontic restoration, if full coverage is not given. On the other hand some of my old root canal treated patients when revisited my clinic for another tooth, I noticed that 10-15 years back root canal treated teeth which has not given full crown are still functioning well without fracture of crown or restoration. This inspires me of doing clinical study and writing an article on post endodontic restoration of sound posterior teeth.

\section{Method \& Materials}

This study is divided into two parts, short study and long study.

In short study views of two hundred private practitioners collected in form of questionnaire prepared on post endodontic restoration of sound posterior teeth. Long study was done in clinic situated in area where mostly lower middle income group people reside. Patients who were not ready for full coverage restoration in continuation after root canal obturation of molar teeth and having restorable tooth structure were selected. Seventy patients with mesio-occlusal or distoocclusal cavity and forty with occlusal cavity of random age and sex were explained about study for which if they are not ready for full crown now, then it cannot be given for further 24 months. Tooth or restoration may get fractured during this period. Patients who agreed for this condition were selected for this study.

The quality of the restorative dentistry performed after root canal treatment directly impacts the prognosis of the endodontically treated tooth. ${ }^{[5]}$ Thus restoration for endodontically treated tooth was designed to protect the remaining tooth structure from fracture and to replace the missing tooth structure with maximum strength. After obturation, gutta-percha points condensed well at the base of pulp chamber. Excess gutta-percha points removed with hot excavator and again well condensed with small round condenser in pulp chamber. As a posterior restorative technic to build resistance form, irregular pulpal floor was made in one plane by giving approximately two $\mathrm{mm}$. thick layer of zincphosphate cement over condensed gutta-percha points. In proximal 
cavity gingival floor was smoothened to make it in parallel plane with pulpal floor. Well triturated and condensed silver amalgam restoration was done in remaining cavity. Proper instructions were given to patients before dispatching. Patients asked to come after three months if there is no problem with that tooth and report immediately if tooth or restoration gets fractured. Follow up study every after 3 month was done for 24 months. Patients whose teeth got fractured during this period and were restorable, convinced for full crown and accordingly full crown were given with core build up. Dislodged restoration removed and rerestoration done. Unrestorable vertically fractured teeth were extracted and replaced with bridge. Full crown were given to the patients who were ready after 24 months. Few patients are still going on without full crown.

\section{Results}

Results of long study are given in Table No. 1 and short study in Table No. 2.

In occlusal restoration for one year, there was no casualty; neither tooth nor restoration got fractured. In a period of 12 to 15 months one tooth, 15 to 18 months two teeth and after 18 months one tooth i.e. in all four teeth were vertically fractured and could not be restored.

In proximal restoration, tooth as well as restoration were alright only for six months. After six months, fractured cusps of two teeth were noticed. During the period of 9 to 12 months, I found three dislodged restoration and vertically fractured two teeth. Two cuspal fractures, two vertical crown fractures and six fractured restorations were found in a period of 12 to 15 months. In 15 to 18 months period cuspal fracture of one tooth, vertical fracture of one tooth and three dislodged restorations were observed. After 18 months except one dislodged restoration, no significant fracture of cusp or tooth noticed. In all in proximal restoration, I found five cuspal fractures, five vertical crown fractures and thirteen dislodged restorations. No horizontal crown fracture was noticed among both the groups.

In occlusal restoration all four teeth were vertically fractured but after 12 months period. In proximal restoration five teeth got cuspal fractures which were restored. But non-restorable vertically fractured teeth were noticed only after nine months. Thus, in all I got $93 \%$ success in proximal restorations and $90 \%$ success in occlusal restorations. So overall success rate in

2 years was $92 \%$, which is similar to the study of Mentink and others who reported $82 \%$ success rate in post endodontically restored tooth after 10 years. Torbjornor and others reported more than $90 \%$ average success rate each year. Nanayorkkara and others reported 17.4 years as average survival rate of post endodontically treated teeth ${ }^{[2]}$.

\section{Discussion}

Posterior teeth bears heavy masticatory load are subject to recurrent non-axial forces. Thus the teeth to resiliently absorb these forces must seal with proper permanent restoration. Teeth with significant remaining natural tooth structure after endodontic treatment must be considered differently from those with extensive loss of tooth structure. When sufficient tooth structure is present to retain the core and crown,in such conditions post are not recommended. Previous research has demonstrated that endodontic access only in otherwise intact tooth has only a minimal effect on the strength of the tooth if restored properly. The key element in the successful restoration of endodontically treated posterior teeth is the placement of proper restoration ${ }^{[4]}$.

Success of endodontic treatment depends on the quality of coronal restoration, which should provide functional marginal sealing and protect the remaining tooth structure ${ }^{[1]}$. Endodontically treated tooth sealed with cement like zinc phosphate, zinc oxide euginol, zinc polycarboxylate or glass ionomer does not fulfill above requirement, as none of the materialposses enough compressive strength to resist occlusal compressive forces and protect remaining tooth structure. Silver amalgam and high strength posterior composite resin should be the choice of material.

Gutta-percha points should be cut as cervically as possible. As it lacks strength it should be condensed at base of pulp chamber. Remove excess gutta-percha with hot excavator and recondensed with round condenser. Remaining excess gutta-percha points in the crown not only weaken the coronal tooth structure, it will also not able to withstand the compressive forces. Vertical compressive forces deviate from the level of condensed gutta-percha points to all peripheries of crown, where already horizontal tensile stresses are acting, which will lead to crown fracture, even if full coverage is given. Vertical forces acting on the restoration generate high tensile stresses while the horizontal forces generate highest tensile stresses at the margin of chamfer and bevel design. (Abu Hassan $\mathrm{M} \mathrm{z}$ in 2000) ${ }^{[6]}$

When cuspal coverage and resistance form to prevent horizontal fracture is required amalgam restorative procedure have proved satisfactorily. ${ }^{1}$ For amalgam restorative procedure base of the cavity should be in one plane. And to make pulpal floor in one plane restorative base is essential. But $63 \%$ of dentists never prefer base below silver amalgam restoration. If permanent restoration like silver is placed directly over condensed gutta-percha points tooth at that level of condensed gutta-percha points may not withstand condensation pressure required for condensing silver amalgam and minute possible cracks may develop in 
remaining tooth structure, which may lead horizontal crown fracture in future. Endodontic procedure reduced tooth stiffness by only $5 \%$ whereas restorative procedures were the greatest contributor towards the loss of tooth stiffness and strength. (Earnest $S$ Rech etc ${ }^{[7]}$ )

It is scientifically proved that IRM containing zinc oxide eugenol has lowest compressive strength, but as removing complete intermediate restorative material and then giving base with high strength cement is time consuming, 58\% dentists prefer reducing IRM dressing as base over condensed gutta-percha points, which should not be done. After condensing gutta-percha points at base of pulp chamber cement base like zinc phosphate, zinc polycarboxylate and glass ionomer cement to withstand condensation pressure as well as vertical compressive forces should be given. $40 \%$ of dentists think that cement base should cover entire gingival floor. In proximal cavities if cement base covers complete gingival floor then it will end at outer surface of prepared cavity. As cement has disadvantage of disintegrating in oral fluid, if given on outer surface of gingival floor, will disintegrate in saliva creating space in between silver amalgam and gingival floor will lead to fracture of silver amalgam restoration, which may again cause secondary caries.

There are many factors, which influences the fracture of endodontically treated tooth. The risk of tooth fracture increases from the beginning of endodontic therapy, so effective temporary and final restorations are mandatory. It has been proposed that a portion of sensory feedback mechanism is lost when neurovascular tissue has been removed from the tooth in the course of endodontic therapy. This mean the patient can inadvertently bite with more force on an endodontically treated tooth than on vital tooth due to the impaired sensory feedback mechanism. ${ }^{2}$ The choice of restorative material and type of cavity preparation should be one that provides maximum protection for the tooth. There should be thorough understanding of forces acting on restoration and tooth because both endodontic and restorative procedures alter the hard tissue. The primary concern is that of resistance form because the tooth must resist both vertical and horizontal forces. Horizontal forces caused the crown to be fractured horizontally from cervical level both in anterior and posterior teeth. Vertical fracture typically occurs in posterior teeth ${ }^{1}$. In this study to provide resistance form to tooth proper base restoration was done and therefore no horizontal crown fractures in both the groups were observed.

In India and especially in developing city like Nagpur where people awareness about saving teeth is increasing, most of the population is of lower middle income group. Even if patients from such population want to save tooth, they cannot afford the expenses of root canal treatment and full crown at a time. Some of them who can afford also feel taxing in their monthly budget. Thus there are so many patients who use to get root canal treatment done and as their pain subsides they delay the full crown treatment. For such patients, if dentist are not serious in giving proper post endodontic restoration, it causes fracture of restoration and even unrestorable fracture of tooth in short time. Trauma of loosing tooth even after paying for root canal treatment creates bad impression of dentists in society.

In this study, all 110 restorations were done with due care. Still in 24 months observation we found thirteen dislodged restoration and five cuspal fracture, which could be restored, but nine vertically fractured teeth could not be restored. After taking $100 \%$ care in doing post endodondic restoration also $16 \%$ restorable and $8 \%$ unrestorable failure were observed in two years. Thus one should be very much serious and carefull in giving proper post endodontic restoration to prevent tooth fracture as we all know root canal treatment saves the tooth but restoration makes it functionable.

\section{Conclusion}

After root canal treatment if post endodontic restoration in posterior teeth is done carefully and systematically, one year waiting period for occlusally restored teeth and nine month waiting period for proximally restored teeth can be considered for full crown, if cannot be given immediately.

In country like India where average people are of lower middle income group who cannot afford too much expenses of root canal treatment and full crown at a time and don't have time to visit government hospital, even if they understand the importance of saving tooth. Such people can get their root canal treatment done first and later on go for full crown within 9-12 months period after post endodontic restoration. Thus it should be part of restorative practice to give proper restoration to endodontically treated posterior tooth so that it should not get fractured in between period of root canal treatment and full crown restoration.

\section{References}

[1] Gillmore, Lund, Balesand and Vernetti - Restoration of endodontically treated teeth.Textbook of Operative Dentistry, $4^{\text {th }}$ edition, $1994: 355-64$

[2] Summit, Robbins, Hilton and Schwartz - Restoration of endonditcally treated teeth. Fundamentals of Operative Dentistry, $3^{\text {rd }}$ edition, 2006: $570-87$.

[3] Hunter AJ - Effect of post placement on endodontically treated teeth. J of Prosthetic Dent, 1989; 62: 166 - 72.

[4] Anil Kishan - Mechanism and risk factor for fracture predilection in endodontially treated teeth. Endodontic Topics, 2006; 13: 57 83.

[5] Ray HA and Trope M - Periapical status of endodontically treated teeth in relation to the technical quality of the root filling and the coronal restoration. Int. Endodontic J, 1995; 28: 8 - 12 . 
[6] Abu Hasan MZ, Abu Hammod OA Harrison A - Stress distribution associated with loaded ceramic only restoration with different design of marginal preparation. J of Oral Rehabilitation, 2000;27 (4): $294-$

[7] Earnest S. Reeh, Harold H Messer \& William Douglas - Reduction in tooth stiffness as a result of endodontic and restorative procedure J of Endodontic, 1989; 15(11): 512.

Table No.1 Observation table for crown \& restoration fracture of molar teeth after post endodontic

\begin{tabular}{|c|c|c|c|c|c|c|c|c|c|c|}
\hline $\begin{array}{l}\text { Type of } \\
\text { restoration }\end{array}$ & $\begin{array}{l}\text { No. of } \\
\text { teeth }\end{array}$ & $\begin{array}{l}0.3 \\
\text { miths. }\end{array}$ & $\begin{array}{l}3-6 \\
\text { moths. }\end{array}$ & $\begin{array}{l}6-9 \\
\text { miths. }\end{array}$ & $\begin{array}{l}9.12 \\
\text { mths. }\end{array}$ & $\begin{array}{l}12-15 \\
\text { mths. }\end{array}$ & $\begin{array}{l}15-18 \\
\text { mths. }\end{array}$ & $\begin{array}{l}18-21 \\
\text { mths. }\end{array}$ & $\begin{array}{l}21-24 \\
\text { mos. }\end{array}$ & Total \\
\hline A Q Qclusal & 40 & & & & & & & & & \\
\hline $\begin{array}{l}\text { Cuspal crown = } \\
\text { Vertical crown } \\
=\end{array}$ & - & - & - & - & - & 1 & 2 & 1 & - & 4 \\
\hline Restoration $=$ & - & - & - & - & - & - & - & - & - & - \\
\hline B. Proxinal & 70 & & & & & & & & & \\
\hline $\begin{array}{l}\text { Cuspal crown = } \\
\text { Vertical crown } \\
=\end{array}$ & - & - & - & 2 & 2 & 2 & 1 & - & - & $\begin{array}{l}5- \\
5\end{array}$ \\
\hline Restoration $=$ & - & - & - & - & 3 & 6 & 3 & - & 1 & 13 \\
\hline
\end{tabular}

Table No. 2 Results of questionnaire answered by practicing dentist Post Endodontic Restoration For Sound Posterior Teeth

\begin{tabular}{|c|c|c|c|}
\hline Sr. & Question & Options & $\begin{array}{l}\text { Marked } \\
\%\end{array}$ \\
\hline 1 & $\begin{array}{l}\text { Your choice of posterior post endodontic } \\
\text { restorative material is }\end{array}$ & $\begin{array}{l}\text { (a) Composite } \\
\text { (b) GIC } \\
\text { (c) Silver Amalgam }\end{array}$ & $\begin{array}{l}28 \% \\
48 \% \\
24 \%\end{array}$ \\
\hline 2. & G.P. Points should be condensed & $\begin{array}{l}\text { (a) up to } 1 / 4 \text { of crown } \\
\text { (b) up to base of pulp chamber } \\
\text { (c) don't bother how much coronal space is } \\
\text { occupied }\end{array}$ & $\begin{array}{l}42 \% \\
37 \% \\
21 \%\end{array}$ \\
\hline 3 & $\begin{array}{l}\text { You give cement base below posterior post } \\
\text { endodontic restoration }\end{array}$ & $\begin{array}{l}\text { (a) Yes } \\
\text { (b) No } \\
\text { (c) Sometimes } \\
\end{array}$ & $\begin{array}{l}10 \% \\
63 \% \\
27 \% \\
\end{array}$ \\
\hline 4 & Your preferable base material is & $\begin{array}{l}\text { (a) Zinc oxide euggenol } \\
\text { (b) Zinc phosphate Zinc polvcorboxylate } \\
\text { (c) GIC }\end{array}$ & $\begin{array}{c}15 \% \\
78 \% \\
7 \%\end{array}$ \\
\hline 5 & Base will cover & $\begin{array}{l}\text { (a) entire gingival floor } \\
\text { (b) entire pulpal floor } \\
\text { (c) Only on condensed G.P. points }\end{array}$ & $\begin{array}{l}40 \% \\
37 \% \\
23 \%\end{array}$ \\
\hline 6 & You will not prefer cement base because & $\begin{array}{l}\text { (a) time consuming } \\
\text { (b) will reduce strength of tooth } \\
\text { (c) don't know }\end{array}$ & $\begin{array}{c}58 \% \\
2 \% \\
40 \%\end{array}$ \\
\hline
\end{tabular}

